\title{
COMO NÃO SE TORNAR UMA PEÇA DE MUSEU $^{1}$
}

\section{Ulrich Beck ${ }^{2}$}

\begin{abstract}
RESUMo
Neste ensaio, quero abordar duas questões que surgiram durante a minha leitura do inspirador artigo de Michael Burawoy. Em primeiro lugar, ao compartilhar de sua perspectiva em favor da recriação do conhecimento [enlightenment] sociológico através da diferenciação entre distintos tipos de sociologias públicas, não compartilho, no entanto, do seu otimismo de que a sociologia pode facilmente tornar-se parte integral da prática e do discurso públicos. Em segundo lugar, não acho que a sociologia convencional esteja realmente preparada para tal empreitada. Meu argumento aponta na direção oposta: as diferentes formas de sociologia pública e não pública estão em risco de se tornarem peças de museu. Assim, a sociologia não precisa apenas de publicização [public voice]: ela precisa, antes, ser reinventada - a fim de poder tornar possível, então, sua publicização .
\end{abstract}

Palavras-chave: Michael Burawoy. Sociologia pública. Cosmopolitismo. Nacionalismo. Desigualdades sociais.

\footnotetext{
${ }^{1}$ Versão original publicada em The British Journal of Sociology, vol. 56, n. 3, de 2005, sob o título "How not to become a museum piece". (C) London School of Economics and Political Science 2005. Reproduzido com permissão de Blackwell Publising Ltd. A Comissão Editorial da revista Mediações agradece aos editores e ao autor por autorizarem esta publicação. Traduzido do inglês pelo College Language Center. Revisão técnica de Léa Tosold.

${ }^{2}$ Sociólogo, professor do Institute of Sociology da Ludwig-Maximilians-Universität (Munique, Alemanha). End. eletrônico: u.beck@lmu.de
} 


\title{
HOW NOT TO BECOME A MUSEUM PIECE
}

\begin{abstract}
In this essay I want to address two question marks which arose during my reading of Michael Burawoy's inspiring piece. First, sharing his spirit of recreating the sociological enlightenment by differentiating between different types of public sociologies, I do not share his optimism that sociology can easily become an integral part of public discourse and practice. Second, I don't think that mainstream sociology is really prepared for this adventure. My argument points in the opposite direction: all the different forms of public and non-public sociology are in danger of becoming museum pieces. Thus, sociology not only needs a public voice, it also needs to be reinvented first - in order to have a public voice at all!
\end{abstract}

Keywords: Michael Burawoy. Public sociology. Cosmopolitanism. Nationalism. Social inequalities.

\section{A SOCIOLOGIA NÃO PRECISA APENAS DE PUBLICIZAÇÃO [PUBLIC VOICE]: ELA PRECISA SER REINVENTADA PARA O SÉCULO XXI}

1 L $\begin{aligned} & \text { ichael Burawoy (2005) escreveu um artigo inspirador: "For public } \\ & \text { sociology". Há anos não havia me sentido tão entusiasmado ou } \\ & \text { concordado tão veementemente com qualquer outro argumento }\end{aligned}$ sociológico. Meu indicador pessoal para isso são os muitos pontos de exclamação que distribuí ao longo do texto. Mas há pontos de interrogação também. Eu quero abordar dois deles aqui. Em primeiro lugar, ao compartilhar de sua perspectiva em favor da recriação do conhecimento [enlightenment] sociológico através da diferenciação entre distintos tipos de sociologias públicas, não compartilho, no entanto, do seu otimismo de que a sociologia pode facilmente tornar-se parte integral da prática e do discurso públicos. Em segundo lugar, não acho que a sociologia convencional esteja realmente preparada para tal empreitada. Meu argumento aponta na direção oposta: as diferentes formas de sociologia pública e não pública estão em risco de se tornarem peças de museu. Assim, a sociologia não precisa apenas de publicização: ela precisa, antes, ser reinventada - a fim de poder tornar possível, então, sua publicização. 


\section{NEM CONHECIMENTO [ENLIGHTENMENT], NEM TECNOLOGIA SOCIAL: OS DIFERENTES MUNDOS DA SOCIOLOGIA ACADÊMICA E DO DISCURSO PÚBLICO}

Michael Burawoy oferece resposta "à crescente diferença [gap] entre o ethos sociológico e o mundo que estudamos". Essa é uma questão muito importante em diversos aspectos, mas ela omite e subestima as diferenças de racionalidade - códigos de comunicação - entre os universos da sociologia acadêmica, por um lado, e os contextos de discurso público, prático e político e de tomada de decisões, por outro. Meu argumento decorre não apenas da experiência pessoal em ambos os domínios. É também resultado de pesquisa acadêmica sobre os "usos da sociologia" em muitos campos. Estou me referindo aos resultados de um programa de pesquisa que organizei no final da década de 1980 e que foi financiado pela Sociedade Alemã de Pesquisa (DFG). No âmbito desse programa, vários projetos tentaram descobrir o que acontece a toda sociologia produzida para fins públicos, práticos ou administrativos quando usada - ou não! - em contextos públicos, práticos e administrativos ${ }^{3}$. A maioria dos sociólogos e das sociólogas parece ter expectativas muito claras e ilusórias quanto à maneira como os resultados de suas pesquisas devem ser usados. Acreditam, muitas vezes, que a sociologia enquanto tal pode ou deve tornar-se uma parte influente de vários discursos não acadêmicos. Desde a década de 1970 tem havido muitas críticas a essa "sabedoria tradicional" [traditional wisdom] (WEISS, 1977) no que tange à sociologia em sua relação com os diferentes domínios de ação social - meios de comunicação de massa, administração pública, negócios, movimentos sociais etc. Um dos resultados disso foram as muitas expressões com base em um novo e inevitável "Colocando a sociologia para trabalhar" (SHOSTAK, 1974). Já outros levantaram a premente questão: "Por que a sociologia não se aplica?" (SCOTT, SHORE, 1979).

Nossosestudos de caso radicalizaram acrítica ao idealismo e ao egocentrismo sociológicos, que parecem esperar um uso "racional", correspondente e direto dos "resultados" das ciências sociais em diferentes contextos. Foi demonstrado empiricamente que o modelo clássico das ciências sociais aplicadas é equivocado - não só não há conexão entre o contexto de produção e o contexto de uso do conhecimento sociológico, como também não existe qualquer relação identificável entre eles. 0 principal resultado de nosso programa de pesquisa foi, a um só tempo,

\footnotetext{
${ }^{3}$ Cf. Beck e Bonß (1989); a relação entre sociologia e práxis/política/público tem sido uma das principais preocupações de meus escritos desde o princípio (BECK, 1972, 1974, 1982).
} 
muito decepcionante e muito desafiador: os usos do conhecimento sociológico não têm nada a ver com o conhecimento sociológico sendo utilizado.

Isso, evidentemente, é fatal tanto para a autointerpretação idealista quanto para as ingênuas esperanças de sociólogos e sociólogas que, naturalmente, desejam influenciar os discursos públicos e os diferentes tipos de práticas políticas e administrativas por meio do conteúdo específico e das implicações do seu trabalho. No entanto, isso também valida uma abordagem mais ponderada e comedida acerca do uso da sociologia na relação entre sociologia e prática, lançando luz sobre os paradoxos que surgem a partir desses diferentes tipos de racionalidade. Claro, um sociólogo ou uma socióloga que tem se empenhado em pesquisar um tema específico durante muitos anos será um pouco como um pai ou uma mãe esperando que seu "filho ou filha" - seus resultados científicos - tenha sucesso no mundo exterior da realidade política. É extremamente difícil tolerar que esses resultados acabem no cesto de papel de um burocrata "ignorante", ou, pior, as decorrentes queixas sobre a "irracionalidade", a "mentalidade fechada", a "ignorância" e as "deformações tecnocráticas" dos usos não sociológicos da sociologia se tornam ensurdecedoras.

Há um lado prático nessa tentativa de realização de pesquisas empíricas sobre os usos da sociologia. Operacionalizando nossos programas de pesquisa, nós começamos com o seguinte princípio: siga o resultado através de seus contextos de uso! Então observamos debates parlamentares, propostas apresentadas por administradores, projetos de leis, medidas administrativas e assim por diante para ver se conseguíamos identificar ali qualquer "conceito", "expressão" ou "conselho prático" que tivesse origem em textos científicos sobre problemas em reforma educacional, política social, comportamento criminoso, política de drogas e assim por diante. Essas tentativas não foram totalmente malsucedidas. Mas, o que encontramos dificilmente poderia vir a ser descrito e interpretado como uso direto de "resultados" científicos. Descobrimos que nossos não sociológicos "colegas sociológicos" [fellow sociologists] (Alvin Gouldner) - profissionais, tomadores de decisões, jornalistas etc. - reinterpretaram tanto o conteúdo sociológico, quanto os chamados "resultados", dentro de seus próprios parâmetros de referência e de acordo com suas próprias finalidades práticas. Nesse processo de intervenção, o "sociologismo" do "resultado" de uma pesquisa sofisticada se perde. E é exatamente esse o modo como a sociologia vem sendo - com sucesso utilizada! Colocando em termos paradoxais: o desaparecimento da sociologia em contextos práticos, públicos e administrativos é precisamente um indicador de uso 
bem-sucedido do conhecimento sociológico! Este segue o paradigma do "boca a boca", um pouco como na brincadeira do "telefone sem fio", em que alguém diz algo à pessoa ao lado, o que é retransmitido de pessoa para pessoa até que, ao final, a mensagem tenha sido transformada em algo completamente diferente, levando todos a um acesso de riso.

Não tenho certeza de quais são as implicações das ideias de Burawoy sobre a sociologia pública. Mas qualquer empenho viável nesse sentido deve estar ciente do fato de que não há correspondência direta entre a sociologia pública e os usos públicos da sociologia pública. Em termos gerais, uma imaginação sociológica re-vitalizada pode ter - e de fato tem - todo tipo de impacto - é possível que haja omissão, mal-entendido e redefinição em favor de todo tipo de interesse. Quando a sociologia pública ou outros tipos de sociologia se tornam parte integrante dos discursos práticos e políticos, elas estão efetivamente sendo "transformadas", isto é, estão sendo despojadas de sua identidade sociológica e "re"-construídas [constructed "anew"] de acordo com os interesses e os objetivos da argumentação prática e da ação.

Uma implicação disso é que, se a sociologia pública não tentar controlar os usuários públicos da sociologia pública, por um lado, e se as pessoas se sentirem livre para usar a sociologia em seus próprios termos e em seus próprios interesses, por outro, não haverá, então, nenhum controle ou expectativa de controle de ambos os lados e a sociologia pública poderá ser provocativa. Ela precisa de posição própria, visão própria, metodologia própria, relação com valores própria (“Wertbeziehung”, Max Weber) e voz própria para ser ouvida nas arenas públicas nacionais - e/ou globais!

Um dos resultados que obtivemos confirma a suposição de Michael Burawoy de que o florescimento de diferentes tipos de sociologia pública é condição para o florescimento da sociologia como um todo. Descobrimos que a resistência, a ignorância e a indiferença, por exemplo, de administrações públicas em relação às constatações de estudos sociológicos (que elas mesmas financiaram) desmoronam quando tais resultados são publicados e discutidos nos meios de comunicação de massa. Então - de repente - os resultados são publicamente reconhecidos e construídos como resultados que têm implicações políticas, de modo que 0 "usuário" tem de reagir a eles. Assim, a posição e a presença públicas da sociologia - a sua publicização [published voice] - produz, coage ou constrói seus usos administrativos, práticos e políticos (quaisquer sejam). 


\section{REINVENTANDO A SOCIOLOGIA PARA O SÉCULO XXI}

Não tenho certeza de não estar interpretando mal o argumento de Burawoy. Se ele está alegando que há uma sociologia convencional e que, além disso, deveriam existir diferentes subdisciplinas de sociologias públicas, duvido que esse modelo de diferenciação seja realmente adequado. Isso porque ele toma por certo o que fundamentalmente tem de ser questionado: todos os diferentes tipos de sociologias públicas, acadêmicas, práticas ou políticas estão em perigo de se tornarem velhas e comuns peças de museu. É o que eu chamo de nacionalismo metodológico.

0 que quero dizer com isso? Quero dizer que a sociologia tem historicamente interesse pela análise das sociedades, sendo cada sociedade baseada em um Estado nacional distinto (ou estado-nação). Portanto, há um sistema de estados-nações e suas respectivas sociologias que estudam uma determinada sociedade definida em termos de estado-nação. 0 estado-nação constitui o receptáculo da sociedade e os limites da "sociologia".

A noção, por exemplo, nos textos de Talcott Parsons, de que cada sociedade é um sistema fechado e autorregulador se torna inválida, ainda que a passos irregulares e com impactos variáveis. Essa tentativa de reinventar a sociologia para o século XXI inclui (pelo menos) duas etapas: primeiro des-construir e depois re-construir a sociologia para a era global. Ilustrarei brevemente as implicações disso em uma área-chave, a da sociologia de classes e desigualdade (BECK, 2005; BECK, SZNAIDER, 2006).

\section{DESCONSTRUÇÃO DA SOCIOLOGIA NACIONAL DAS DESIGUALDADES SOCIAIS}

Há pelo menos duas possíveis respostas à questão sobre o que é que legitima a desigualdade: o sistema de mérito e o princípio do estado-nação. A primeira resposta é familiar e veio sendo tanto elaborada quanto criticada; deriva da autocompreensão da perspectiva nacional e diz respeito às desigualdades dentro dos limites do Estado. A segunda resposta advém do parâmetro de referência da perspectiva cosmopolita e está relacionada à "legitimação" das desigualdades globais. Assim, somente alternando sistematicamente entre as perspectivas nacional e cosmopolita é que os grandes pontos cegos - e fontes de erro - presentes no nacionalismo metodológico da pesquisa sobre desigualdade 
podem vir a ser identificados. Apenas no contexto de tal Nova Teoria Crítica das desigualdades sociais é que a assimetria fundamental de percepções de desigualdade vinculadas à perspectiva nacional pode ser revelada a partir de ambos pontos de vista: o social e o das ciências sociais. Isso esclarece o fato de que o "êxito legitimador" do estado-nação encontra-se em chamar a atenção das pessoas exclusivamente para assuntos internos, banindo assim as desigualdades globais do campo de visão dos (relativamente) privilegiados.

Faz sentido meramente em termos espaciais diferenciar entre grandes desigualdades (que, por sua vez, podem ser divididas em transnacionais, supranacionais, internacionais e globais) e pequenas desigualdades. As "pequenas" desigualdades estão localizadas dentro do estado-nação e, por razões perfeitamente compreensíveis, parecem ser grandes para indivíduos e grupos afetados por elas; no entanto, do ponto de vista cosmopolita elas são pequenas, pois coincidem com as estruturas de autodescrição, autoatribuição e automonitoramento do estado-nação. 0 sistema de mérito aloca as desigualdades dentro do Estado ao mesmo tempo em que as legitima. Um paradigma adequado para descrever essa situação é o do exame escrito: todos entram em condições iguais, mas saem em condições desiguais (com diferentes posições na hierarquia de notas). Com o sistema de mérito, por exemplo, a distribuição de renda pode ser ao mesmo tempo desigual $e$ legítima. Em contraste, falar do princípio do estadonação como "legitimação" das desigualdades sociais significa que o foco do estado-nação nas desigualdades nacionais faz com que as desigualdades globais desapareçam - legitima-se ocultando. As grandes desigualdades são banidas além dos limites da perspectiva nacional. 0 que resulta disso é que elas podem tanto crescer quanto ser "legitimadas" enquanto institucionalmente irrelevantes ou irreais. Assim, as grandes desigualdades são "legitimadas" não tanto pela falta de interesse e debate sobre as desigualdades globais, mas sim por interesse e debate a respeito das "pequenas" desigualdades nacionais.

A distinção entre "grande" e "pequena" se refere portanto a espaços de percepção e estimativas populacionais. Evidentemente, esse preceito da exclusão das desigualdades globais pelo estado-nação apontado acima é estremado - a particularidade nacional de um Estado geralmente não descarta a possibilidade de princípios e percepções universais. No entanto, é certo dizer que a perspectiva do estado-nação "liberta" as pessoas de ter de olhar para a miséria no mundo. Ela funciona com base em uma dupla exclusão: exclui os excluídos. A estabilidade com que as grandes desigualdades sofridas pela humanidade são "legitimadas" em 
silenciosa cumplicidade entre a autoridade estatal e as ciências sociais centradas no Estado, através da não percepção organizada, é surpreendente.

\section{RECONSTRUINDO A SOCIOLOGIA TRANSNACIONAL DAS DESIGUALDADES}

Meu argumento, atéentão, játem se mostrado parte de uma nova abordagem "transnacional" (não confundir com "internacional") das desigualdades sociais. Um campo totalmente novo para a pesquisa e a teoria sociológicas além das fronteiras começa aqui a ser delineado. Precisamos de novas definições sobre a unidade da pesquisa, novas conceitualizações e teorias de transnacionalização, novas formas de organização de pesquisa etc.

A fim de ilustrar essa transformação necessária de todos os tipos de sociologias (pública, profissional, política etc.), pergunto: o que confere estabilidade à "legitimação" (negativa) das desigualdades globais através do silêncio diante da crescente permeabilidade das fronteiras? 0 que a desestabiliza? Quatro princípios de construção de irrelevância e irrealidade por parte do estadonação podem ser identificados aqui.

0 primeiro deles é o princípio de fragmentação do estado-nação e imputabilidade das desigualdades globais. Enquanto não existir uma autoridade global responsável por monitorar as desigualdades globais, estas se desintegram em fragmentos de desigualdades nacionais. Para cada um dos cerca de 200 Estados existentes hoje, há aproximadamente 200 modos de observar e avaliar a relevância das pequenas desigualdades sociais. Contudo, a soma dessas desigualdades internas registradas por cada um dos estados-nações de maneira alguma equivale ao total das grandes desigualdades globais, porque a lógica da perspectiva nacional não é a mesma da perspectiva cosmopolita. Em particular, a autoatribuição do estado-nação e sua consequente premissa de causalidade endógena contradizem o ponto de vista cosmopolita, que também faz referência a interdependências transnacionais, relações de poder, órgãos tomadores de decisões e causalidades a fim de explicar as desigualdades internas do estado-nação.

0 princípio do estado-nação é a chave analítica para entender por que a conexão entre globalização e pobreza tem sido tão pouco pesquisada na sociologia, que aindaéprisioneira do estado-nação. Enquanto a perspectiva nacional continuar exercendo influência na esfera da ação política, bem como na análise das ciências 
sociais, a pobreza e a riqueza permanecerão sendo detectadas apenas dentro do contexto nacional. A própria possibilidade de que as consequências negativas da globalização pudessem fazer-se sentir em diferentes contextos históricos - em forma de desigualdades crescentes, erosão dos salários, exploração dos recursos naturais e corrosão da democracia - encontra-se descartada analiticamente. No que tange a pesquisa das ciências sociais sobre a desigualdade, o princípio de fragmentação do estado-nação está ligado, portanto, a uma grande fonte de erro: 0 perigo de se chegar a falsas conclusões a partir de premissas do estado-nação.

0 segundo princípio é o seguinte: a percepção das desigualdades sociais pressupõe normas de igualdade. Do ponto de vista do estado-nação, a estabilidade com que as grandes desigualdades são excluídas baseia-se na validade das normas nacionais de igualdade, sejam elas definidas em termos de cultura, etnicidade, leis ou política. A objetividade das desigualdades sociais globais não é posta politicamente em questão enquanto elas permanecem à sombra de normas institucionalizadas de igualdade. Dessa maneira, conforme as normas nacionais de igualdade são substituídas pelas cosmopolitas, a necessidade e a urgência de conferir legitimação por parte do Estado às grandes desigualdades existentes consequentemente crescem. Em que essa igualdade interna aos estadosprovidência ocidentais é baseada, dentro do paradigma nacional? Na igualdade formal decorrente do status de ser um cidadão ou uma cidadã: as diferenças de renda entre homens e mulheres, as diferenças em relação a onde as pessoas vivem, entre outras, não devem servir de base para classificar cidadãos e cidadãs em termos do seu status. Todos os membros de uma nação têm os mesmos direitos e responsabilidades. Essa igualdade legalmente sancionada entre os cidadãos de um Estado é sustentada pelo modelo de homogeneidade cultural do estado-nação (mesma língua, mesma história, mesmas tradições culturais). Tais princípios nacionais de inclusão e exclusão servem tanto para determinar quanto para estabilizar os limites da percepção das pessoas sobre as desigualdades sociais.

Isso leva a um terceiro princípio, o da não comparabilidade das desigualdades sociais entre os estados-nações. A perspectiva nacional e a "capacidade funcional" do estado-nação para legitimar as desigualdades globais residem não menos no fato de que politizar comparações só se sustenta intranacionalmente, nunca internacionalmente. Deslegitimar comparações, por sua vez, pressupõe normas nacionais de igualdade. Nesse sentido, por exemplo, desigualdades de renda entre nigerianos e alemães, sul-americanos e finlandeses, russos e chineses, turcos e coreanos podem ser tão grandes quanto queiram, 
ainda que dadas as mesmas qualificações e os mesmos perfis para o cargo, mas o potencial deslegitimador dessas comparações só é sentido se ocorrem dentro de um parâmetro comum de percepções da igualdade institucionalizada. Esse poderia ser o caso, por exemplo, da associação [membership] a uma nação ou a uma corporação global.

Uma questão interessante que emerge disso tudo é até que ponto as diferenças internacionais de renda dentro da União Europeia podem continuar a ser legitimadas no futuro pelo princípio da não comparabilidade; ou até que ponto, com o aumento da autoconsciência europeia (e da institucionalização da auto-observação europeia), desigualdades que até agora têm sido desconsideradas internacionalmente passarão a ser percebidas como desigualdades intranacionais e, portanto, terão de ser legitimadas (BECK, 2005). À medida que as barreiras para se comparar as desigualdades entre os estados-nações forem caindo (independente do motivo), a União Europeia deve esperar entrar numa fase de graves turbulências, mesmo se as condições de desigualdade permanecerem constantes. No entanto, 0 papel do estado-nação no sistema de desigualdades globais de modo algum se esgota em sua assim chamada função legitimadora.

0 quarto princípio é o seguinte: desconsiderar legitima a inação, ou melhor, legitima ações que tornam pior as grandes desigualdades porque, para a perspectiva nacional, esses efeitos "externos" encontram expressão em uma irrealidade predeterminada, ou seja, eleitoralmente irrelevante. Ao falar sobre desigualdades sociais como se fossem exclusivamente "caseiras" [home grown], torna-se possível conduzir uma política global de redistribuição em que os riscos são exteriorizados e transmitidos aos países mais fracos do terceiro mundo, ao passo que quaisquer benefícios são maximizados no contexto nacional.

Enquanto os estadistas ocidentais se entusiasmavam com o fato de havermos desfrutado de uma década de paz e prosperidade inesperadas, um número crescente de países se afundava ainda mais em dívidas e desemprego, além de testemunhar o declínio de seus serviços de saúde e sociais, bem como os de infraestrutura, tão urgentemente necessários. 0 que pode se bem útil para empresas ocidentais, por exemplo, uma rigorosa aplicação de desregulamentação, privatização e uma maior flexibilidade nos países em desenvolvimento, para estes é, muitas vezes, desastroso.

Resumindo os princípios: a ordem mundial do estado-nação fragmenta as desigualdades globais; as normas nacionais de igualdade excluem as 
desigualdades globais; a comparabilidade intranacional das desigualdades garante a incomparabilidade internacional; e a irrelevância das desigualdades em escala global é predeterminada. Todos esses princípios tornam possível que os ricos e poderosos estados-nações transmitam os riscos decorrentes de suas decisões para os Estados mais pobres, uma prática consolidada não menos pelo fato de que 0 nacionalismo metodológico das ciências sociais valida e promove ações com base na perspectiva nacional. A pesquisa sobre desigualdade baseada nessa abordagem constitui miopia nacional e transforma o objeto de pesquisa e a si mesma em "ciência autóctone" [native science] do estado-nação. Algo que em outro lugar seria considerado problemático desde o ponto de vista científico - a pesquisa autoorientada - passa aqui a ser aclamado como princípio metodológico. Na melhor das hipóteses, esse autismo nacional é estendido a um autismo comparativo na linha dos estudos comparativos internacionais. Mas, mesmo tal nacionalismo metodológico comparativo permanece apegado aos grandes equívocos próprios do nacionalismo metodológico.

Nesta era global, a sociologia necessita urgentemente de uma Nova Teoria Crítica com aspirações cosmopolitas: é preciso revelar e desmantelar o muro do nacionalismo metodológico construído sobre sistemas de classificação e rotinas de pesquisa das ciências sociais para que esta possa, por exemplo, pôr em evidência o papel legitimador do estado-nação dentro do sistema de grandes desigualdades. Os já existentes mapeamentos internos de desigualdades sociais nacionais são sofisticados, altamente detalhados e geralmente até mesmo adequados para lidar com o consequente potencial de protesto por parte dos relativamente privilegiados entre a população mundial no âmbito estatal. Mas, os demônios que habitam os grandes, desconhecidos e absolutamente subpesquisados universos de desigualdade deixaram de ser meros temas decorativos que servem para enfeitar as margens. A crença no estado-nação, juntamente com as narrativas nacionais que dominam o discurso público e a pesquisa acadêmica, certamente não pode ser negligenciada ou ignorada. Mas, desde os ataques terroristas de 11 de setembro de 2001, se não já antes, muitas pessoas passaram a se dar conta de que, a fim de poder olhar através das brechas no muro da percepção que separa as "pequenas" das "grandes" desigualdades, é preciso baixar e pôr de lado as armas que temos apontadas diante dos olhos.

A ideia é que apenas a perspectiva cosmopolita, em seu compromisso com a realidade, pode revelar os desastres que nos ameaçam neste início do século XXI. A Teoria Crítica investiga as contradições, os dilemas, bem como os invisíveis e 
não intencionais efeitos colaterais de uma modernidade que estáse tornando mais cosmopolita; ela extrai seu poder crítico definidor da tensão entre a autodescrição política e a observação das ciências sociais sobre uma mesma questão. A teoria é a seguinte: a perspectiva cosmopolita abre espaços e estratégias para ações que a perspectiva nacional bloqueia. Essa interpretação ganha maior plausibilidade devido ao fato de que o espaço para ação aberto pela perspectiva cosmopolita contradiz a falta de alternativas diagnosticada por políticos e cientistas sociais na perspectiva nacional.

\section{REFERÊNCIAS}

BECK, Ulrich. Soziologische normativität. Kölner Zeitschrift für Soziologie, v. 24, p. 201-32, 1972.

. Objektivität und normativität. Die theorie-praxis-debatte in der modernen deutschen und amerikanischen Soziologie. Reinbek, b. Hamburg: Rowohlt, 1974.

. Folgeprobleme der modernisierung und die stellung der soziologie in der praxis. In: BECK, Ulrich (Org.). Soziologie und praxis, sonderband soziale welt. Göttingen: Schwartz, 1982.

. Power in the global age. Cambridge: Polity Press, 2005.

BECK, Ulrich; BONß, Wolfgang (Org.). Weder sozialtechnologie noch Aufklärung. Frankfurt a. Main: Suhrkamp, 1989.

BECK, Ulrich; SZNAIDER, Natan. Unpacking cosmopolitanism for the social sciences: a research agenda. The British Journal of Sociology, v. 57, n. 1, p. 1-23, 2006.

BURAWOY, Michael. For public sociology. The British Journal of Sociology, v. 56, n. 2, p. 259-94, 2005.

SCOTT, Robert; SHORE, Arnold. Why sociology does not apply? New York: Elsevier, 1979 .

SHOSTAK, Arthur B. Putting sociology to work. New York: MacKay, 1974.

WEISS, Carol (Org.). Using social research for public policy making. Lexington: Lexington Books, 1977. 